\title{
Typical case of narcolepsy in paediatrics
}

\author{
Mariana Portela, ${ }^{1}$ Mariana Leitão Santos, ${ }^{1}$ Carla Moreira, ${ }^{1}$ Marta Rios ${ }^{2}$
}

${ }^{1}$ Paediatrics, Hospital de Braga, Braga, Portugal

${ }^{2}$ Pediatrics, Centro Hospitalar Universitário do Porto EPE Centro Materno-Infantil do Norte Dr Albino Aroso, Porto, Portugal

\section{Correspondence to} Dr Mariana Portela; mariana.fpo@hotmail.com

Accepted 11 May 2021

\section{DESCRIPTION}

An 8-year-old boy was presented to the emergency department with a 15-day history of excessive daytime sleepiness (EDS). In addition to sleeping a duration of 10 hours overnight, he also initiated a daily nap. Extreme drowsiness occurred while watching television, playing computer or eating. Brief episodes of knee weakness happened when laughing which embarrassed him. An aggressive behaviour and an increased appetite were also noted. Night sleep was restless, with periods of speech, awakenings and snoring. School performance remained unaffected. Cataplectic face, with eyelid ptosis (video 1), was observed and the remaining examination was unremarkable. Brain MRI scan was normal. He then underwent an overnight polysomnography (PSG), showing sleep efficiency of $77.8 \%$ and fragmented sleep (21 awakenings), without significant apneas, hypopnoeas or periodic leg movements. A multiple sleep latency test (MSLT) was also performed, revealing hypersomnia (average latency $7 \mathrm{~min} 22 \mathrm{~s}$ ) and three sleeponset rapid eye movement (REM) periods, allowing diagnosis of Narcolepsy. HLA-typed has HLADQB1*06:02. Besides sleep hygiene measures and frequent naps, treatment was initiated with methylphenidate. Once episodes of cataplexy become more frequent fluoxetine was started. He had a good outcome, however, developed some abnormal perioral movements.

Narcolepsy type I is a disabling chronic condition, characterised by EDS, ${ }^{12}$ with irresistible sleep attacks, most often during passive activities. ${ }^{1}$ It is a rare disease, occurring in $0.025 \%-0.050 \%$ of the general population and is typically diagnosed in the second or third decade of life. ${ }^{12}$ It is associated with loss of the neuropeptide orexin (hypocretin), in the lateral and posterior hypothalamus, which is responsible, among other, for maintaining awakefulness. ${ }^{13}$ Its association with HLA DQB1*06:02, suggests an autoimmune basis. ${ }^{13}$

Clinical presentation includes hypnogogical/ hypnopompic hallucinations, disturbed nocturnal



Video 1 Cataplectic face with eyelid bilateral ptosis sleep, sleep paralysis and cataplexy. ${ }^{2}$ Cataplexy, defined as an abrupt, brief episode of loss of voluntary muscle tone, with consciousness retained, is only present in type $1 .^{1-3}$ This feature is observed in $60 \%-70 \%$ of these patients, being the most typical symptom, ${ }^{2}$ and it is usually triggered by strong emotions, mostly laughter. ${ }^{1}$ Cataplexy can be present concomitantly with EDS or within $1-3$ years. ${ }^{1}$ Children present mainly facial involvement, receiving the term 'cataplectic face', consisting of bilateral ptosis, mouth opening and tongue protrusion. ${ }^{4}$ However, more complex movement disturbances, such as perioral movements, can be present. ${ }^{1-3}$ Children with narcolepsy may also develop hyperactivity, aggressiveness, distractibility and restlessness. Rapid weight gain and precocious puberty are frequent. ${ }^{1}$

MSLT with an average sleep latency $\leq 8$ minutes and $\geq 2$ sleep-onset REM periods with a normal PSG, allows diagnosis of narcolepsy. ${ }^{13}$ Low hypocretin in cerebrospinal fluid is found in some patients with narcolepsy type $1 .{ }^{1}$

Regarding pharmacological therapies, stimulant therapy is used as primary treatment, to improve functioning and alertness. Tricyclic antidepressants, sodium oxybate, selective serotonin reuptake inhibitors, serotonin and norepinephrine reuptake inhibitors are helpful to decrease cataplexy. ${ }^{2}{ }^{3}$ Sodium oxybate can also be effective in EDS. ${ }^{24}$ Treatment should be personalised; scheduled brief naps and a good sleep hygiene can be very helpful. ${ }^{23}$

\section{Patient's perspective}

'Narcolepsy changed part of my life. To stay awake, especially in class, I have to take the medication in the morning. In terms of school performance it didn't affect me. What bothers me most is the cataplexy, because when I laugh, I lose my strength and I have to be careful not to fall. I hope that 1 day they will find a cure.'

\section{Learning points}

- Narcolepsy is a rare disease, characterised by excessive daytime sleepiness not explained by other causes.

(c) BMJ Publishing Group Limited 2021. No commercial re-use. See rights and permissions. Published by BMJ.

To cite: Portela $\mathrm{M}$ Santos ML, Moreira C, et al. BMJ Case Rep

2021:14:e241343.

doi:10.1136/bcr-2020-

241343
- Cataplexy is associated in $60 \%-70 \%$ of the cases, being the most specific symptom of narcolepsy type 1 . Its presentation in children includes ptosis with tongue protrusion (catapletic face) and/or hypotonic attacks.

- This condition has an important impact on quality of life of the patient and his caregivers. 
Contributors MP, MLS and CM were involved in clinical diagnosis and patient's initial care. MR is involved in the subsequent follow up of the patient. MP drafted the manuscript, and all authors contributed substantially to its revision.

Funding The authors have not declared a specific grant for this research from any funding agency in the public, commercial or not-for-profit sectors.

Disclaimer Case reports provide a valuable learning resource for the scientific community and can indicate areas of interest for future research. They should not be used in isolation to guide treatment choices or public health policy.

Competing interests None declared.

Patient consent for publication Parental/guardian consent obtained.
Provenance and peer review Not commissioned; externally peer reviewed.

\section{REFERENCES}

1 Plazzi G, Clawges HM, Owens JA. Clinical characteristics and burden of illness in pediatric patients with narcolepsy. Pediatr Neurol 2018;85:21-32.

2 Morse AM. Narcolepsy in children and adults: a guide to improved recognition, diagnosis and management. Med Sci 2019;7:106.

3 Nallu S, Guerrero GY, Lewis-Croswell J, et al. Review of narcolepsy and other common sleep disorders in children. Adv Pediatr 2019;66:147-59.

4 Pillen S, Pizza F, Dhondt K, et al. Cataplexy and its mimics: clinical recognition and management. Curr Treat Options Neurol 2017;19:23.

Copyright 2021 BMJ Publishing Group. All rights reserved. For permission to reuse any of this content visit

https://www.bmj.com/company/products-services/rights-and-licensing/permissions/

BMJ Case Report Fellows may re-use this article for personal use and teaching without any further permission.

Become a Fellow of BMJ Case Reports today and you can:

- Submit as many cases as you like

- Enjoy fast sympathetic peer review and rapid publication of accepted articles

- Access all the published articles

Re-use any of the published material for personal use and teaching without further permission

\section{Customer Service}

If you have any further queries about your subscription, please contact our customer services team on +44 (0) 2071111105 or via email at support@bmj.com.

Visit casereports.bmj.com for more articles like this and to become a Fellow 